\title{
Classification of hepatic venous tumor thrombus in hepatocellular carcinoma: should it describe tumor status or predict patient survival?
}

\author{
Norihiro Kokudo, Wei Tang, Takashi Kokudo \\ Department of HPB Surgery, National Center for Global Health and Medicine, Tokyo, Japan \\ Correspondence to: Norihiro Kokudo, MD, PhD, FACS, FRCS. National Center for Global Health and Medicine, 1-21-1 Toyama, Shinjuku-ku, Tokyo \\ 162-8655, Japan. Email: nkokudo@hosp.ncgm.go.jp. \\ Comment on: Chen ZH, Wang K, Zhang XP, et al. A new classification for hepatocellular carcinoma with hepatic vein tumor thrombus. Hepatobiliary \\ Surg Nutr 2020;9:717-28.
}

Submitted Jun 11, 2021. Accepted for publication Jun 28, 2021.

doi: 10.21037/hbsn-21-237

View this article at: https://dx.doi.org/10.21037/hbsn-21-237

Tumor thrombus in the hepatic veins or inferior vena cava (HVTT/IVCTT) is the second most common of the three types of vascular invasion by hepatocellular carcinoma (HCC). According to the most recent nationwide survey in Japan, vascular invasion of the portal vein (PVTT) is present $13.2 \%$ of newly diagnosed HCCs, followed by HVTT/IVCTT $(6.2 \%)$ and bile duct tumor thrombus (BDTT, 3.4\%) based on imaging findings (1). Because of the relative rarity of HVTT/IVCTT, only a few studies have reported on the classification and treatment of this type of vascular invasion (2-4).

In this issue of HSBN, Chen et al. have proposed a new classification for HVTT/IVCTT with the highest discriminative ability to stratify patient outcomes (5). The discriminative ability of this stratification remained high even when patients were subdivided by treatment modality. The Japanese classification of HCC is one of the oldest and probably most often used in the event of vascular invasion. It was proposed back in 1983 (6) categorizing HVTT as tumor thrombus in a peripheral hepatic vein (pHVTT, $\mathrm{V}_{\mathrm{v} 1}$ ), a major hepatic vein (mHVTT, $V_{v} 2$ ), or the inferior vena cava (IVCTT, Vv3, Figure 1). This classification is very simple and easy to apply while also yielding sufficient information with which to select the appropriate procedure. However, it may not have been developed to predict patient survival. In fact, patients with pHVTT $\left(V_{v} 1\right)$ or mHVTT $\left(V_{v} 2\right)$ are reported to have almost identical OS curves (7). In contrast, patient outcomes of IVCTT have uniformly been poor and this patient subpopulation is small, which is why sub-classification of IVCTT has rarely been attempted (8).

According to the nationwide survey in Japan mentioned at the start, a total of 18,139 new cases of HCC were registered with diagnostic imaging for HVTT/IVCTT (1). Of these, 501 (2.8\%) had pHVTT (image-Vv1), 352 (1.9\%) with mHVTT (image-Vv2), and 261 (1.4\%) with IVCTT (image$\mathrm{Vv3}$ ). Given the small number of patients with IVCTT and their very poor outcomes, assembling sufficient data to subclassify patients with IVCTT has been extremely difficult. Chen et al. collected data on 291 patients with IVCTT over an 8-year period from a SINGLE Chinese high-volume center; this outnumbers the entire Japanese biannual national patient registry (5). Subclassifying IVCTT based on the location of the tip of the tumor thrombus (Type IIIa or IIIb) may be reasonable because cardiopulmonary bypass is required to resect IVCTT extending into the right atrium. This classification is in line with Types I, II, and III according to Li et al. (8). However, the border between the IVC and right atrium is difficult to identify on imaging, and the suprahepatic portion of the IVC can be elongated by meticulous dissection of the IVC and division of the subphrenic veins. If the tumor thrombus does not extensively protrude into the right atrium, use of cardiopulmonary bypass can be avoided. Using the level of the diaphragm as a landmark for subclassification, as Chen et al. proposed, is therefore highly reasonable. Subclassifying the Japanese category of IVCTT (Vv3) into IVCTTb (Vv3b: below diaphragm, Figure 1C) and IVCTTa (Vv3a: above diaphragm, Figure 1D), as an example, may warrant consideration. 

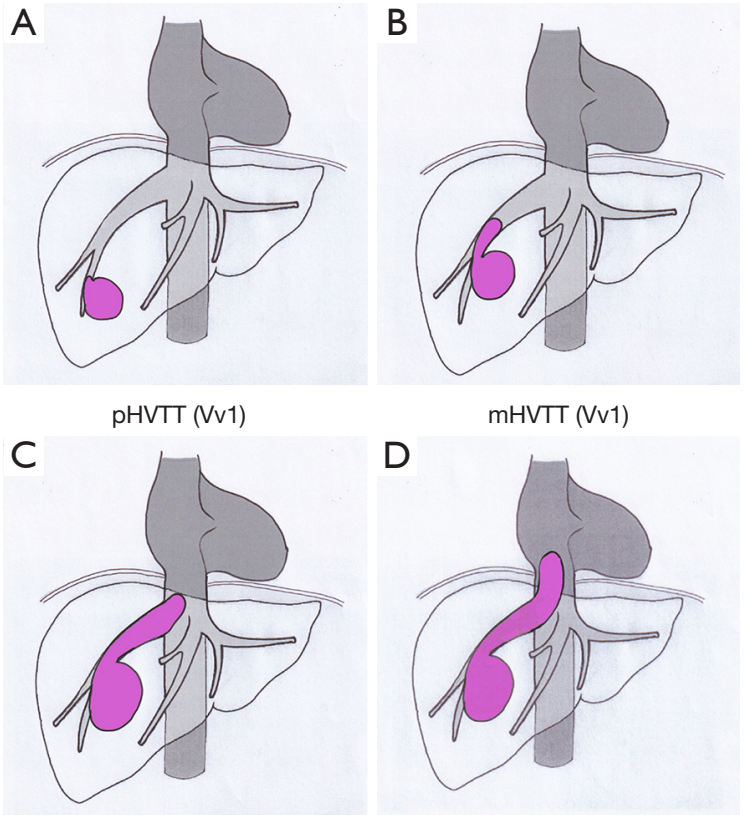

IVCTT (Vv3)

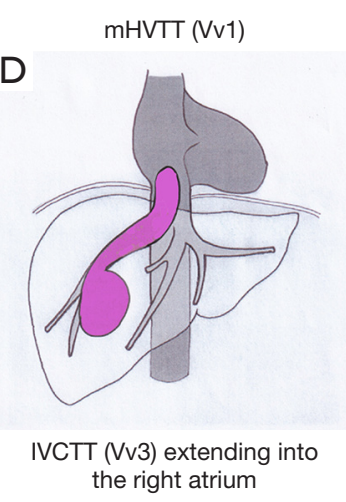

Figure 1 Diagram of the Japanese classification of HVTT/ IVCTT (6). (A) tumor thrombus (TT) in a peripheral hepatic vein (pHVTT, Vv1), (B) TT in a major hepatic vein (mHVTT, Vv2), (C) TT in the inferior vena cava (IVCTT, Vv3), (D) IVCTT extending into the right atrium.

However, such a classification may not necessarily predict patient outcome. The classification proposed by Chen et al. was the same for patients undergoing surgery, and it was remarkably useful in stratifying patient outcomes. Since this study is based on patient data from a single center and information on the pattern of recurrence was not available, this finding should be verified in a multicenter cohort study or based on patient registries in countries where HBV infection is not the major cause of HCC.

\section{Acknowledgments}

Funding: None.

\section{Footnote}

Provenance and Peer Review: This article was commissioned by the editorial office of Hepatobiliary Surgery and Nutrition. The article did not undergo external peer review.
Conflicts of Interest: All authors have completed the ICMJE uniform disclosure form (available at https://hbsn. amegroups.com/article/view/10.21037/hbsn-21-237/coif). Dr. $\mathrm{NK}$ and WT serve as the unpaid editorial board members of Hepatobiliary Surgery and Nutrition. Dr. NK reports lecture fees from AstraZeneka. TK has no conflicts of interest to declare.

Ethical Statement: The authors are accountable for all aspects of the work in ensuring that questions related to the accuracy or integrity of any part of the work are appropriately investigated and resolved.

Open Access Statement: This is an Open Access article distributed in accordance with the Creative Commons Attribution-NonCommercial-NoDerivs 4.0 International License (CC BY-NC-ND 4.0), which permits the noncommercial replication and distribution of the article with the strict proviso that no changes or edits are made and the original work is properly cited (including links to both the formal publication through the relevant DOI and the license). See: https://creativecommons.org/licenses/by-nc$\mathrm{nd} / 4.0 /$.

\section{References}

1. Kudo M, Izumi N, Kokudo N, et al. Report of the 21st Nationwide Follow-up Survey of Primary Liver Cancer in Japan (2010-2011). Hepatol Res 2021;51:355-405.

2. Ito K, Takemura N, Inagaki F, et al. Difference in treatment algorithms for hepatocellular carcinoma between world's principal guidelines. Glob Health Med 2020;2:282-91.

3. Qiu G, Jin Z, Chen X, et al. Interpretation of guidelines for the diagnosis and treatment of primary liver cancer (2019 edition) in China. Glob Health Med 2020;2:306-11.

4. Kokudo T, Hasegawa K, Matsuyama Y, et al. Liver resection for hepatocellular carcinoma associated with hepatic vein invasion: A Japanese nationwide survey. Hepatology 2017;66:510-7.

5. Chen ZH, Wang K, Zhang XP, et al. A new classification for hepatocellular carcinoma with hepatic vein tumor thrombus. Hepatobiliary Surg Nutr 2020;9:717-28.

6. Liver Cancer Study Group of Japan. General Rules for the Clinical and Pathological Study of Primary Liver Cancer. 
1st ed. Tokyo: Kanehara \& Co., Ltd., 1983.

7. Kokudo T, Hasegawa K, Yamamoto S, et al. Surgical treatment of hepatocellular carcinoma associated with hepatic vein tumor thrombosis. J Hepatol 2014;61:583-8.

Cite this article as: Kokudo N, Tang W, Kokudo T. Classification of hepatic venous tumor thrombus in hepatocellular carcinoma: should it describe tumor status or predict patient survival? HepatoBiliary Surg Nutr 2021;10(4):538540. doi: 10.21037/hbsn-21-237
8. Li AJ, Zhou WP, Lin C, et al. Surgical treatment of hepatocellular carcinoma with inferior vena cava tumor thrombus: a new classification for surgical guidance. Hepatobiliary Pancreat Dis Int 2013;12:263-9. 